\title{
Novel T cells with improved in vivo anti-tumor activity generated by RNA electroporation
}

\author{
Xiaojun Liu ${ }^{1,2}$, Shuguang Jiang ${ }^{2}$, Chongyun Fang ${ }^{2}$, Hua $\mathrm{Li}^{2}$, Xuhua Zhang ${ }^{2}$, Fuqin Zhang ${ }^{2}$, Carl H. June ${ }^{2,3}$, \\ Yangbing Zhao, ${ }^{2, \bigotimes}$ (D) \\ ${ }^{1}$ Key Laboratory for Experimental Teratology of Ministry of Education and Department of Immunology, School of Basic Medical \\ Sciences, Shandong University, Jinan 250012, China \\ ${ }^{2}$ Center for Cellular Immunotherapies, University of Pennsylvania Cancer Center, Philadelphia, PA 19104, USA \\ ${ }^{3}$ Department of Pathology and Laboratory Medicine, Perelman School of Medicine, University of Pennsylvania, Philadelphia, \\ PA 19104-5156, USA \\ $\triangle$ Correspondence: Yangbing@upenn.edu (Y. Zhao)
}

Received February 16, 2017 Accepted April 20, 2017

\begin{abstract}
The generation of $\mathrm{T}$ cells with maximal anti-tumor activities will significantly impact the field of T-cellbased adoptive immunotherapy. In this report, we found that OKT3/IL-2-stimulated T cells were phenotypically more heterogeneous, with enhanced anti-tumor activity in vitro and when locally administered in a solid tumor mouse model. To further improve the OKT3/IL-2-based T cell manufacturing procedure, we developed a novel $T$ cell stimulation and expansion method in which peripheral blood mononuclear cells were electroporated with mRNA encoding a chimeric membrane protein consisting of a single-chain variable fragment against CD3 and the intracellular domains of CD28 and 4-1BB (OKT3-28BB). The expanded T cells were phenotypically and functionally similar to T cells expanded by OKT3/LL-2. Moreover, co-electroporation of CD86 and 4-1BBL could further change the phenotype and enhance the in vivo anti-tumor activity. Although T cells expanded by the coelectroporation of OKT3-28BB with CD86 and 4-1BBL showed an increased central memory phenotype, the $T$ cells still maintained tumor lytic activities as potent as those of OKT3/LL-2 or OKT3-28BB-stimulated T cells. In different tumor mouse models, $T$ cells expanded by OKT3-28BB RNA electroporation showed anti-tumor activities superior to those of OKT3/LL-2 T cells. Hence, T cells with both a less differentiated phenotype and
\end{abstract}

Electronic supplementary material The online version of this article (doi:10.1007/s13238-017-0422-6) contains supplementary material, which is available to authorized users. potent tumor killing ability can be generated by RNA electroporation, and this $\mathrm{T}$ cell manufacturing procedure can be further optimized by simply co-delivering other splices of RNA, thus providing a simple and cost-effective method for generating high-quality $T$ cells for adoptive immunotherapy.

KEYWORDS T lymphocytes, CAR, manufacture, gene transfer, RNA electroporation

\section{INTRODUCTION}

T lymphocytes can be modified by gene transfer to enhance their specific anti-tumor activities for cancer treatment (Brentjens et al., 2013; Lee et al., 2015; Morgan et al., 2006; Porter et al., 2011). To further improve this therapeutic approach, efforts are underway to define and generate better $T$ cells. In general, T lymphocytes must be expanded to sufficient quantities before use. Several ex vivo cell manufacturing platforms can be used to produce clinical-grade products with large numbers of $T$ cells for adoptive immunotherapy trials. These approaches include the use of anti-CD3/CD28 beads (Levine et al., 1997), the direct addition of anti-CD3 antibodies to peripheral blood mononuclear cells (PBMCs) in the presence of IL-2 (OKT3/L-2) (Riddell and Greenberg, 1990) and cell-based artificial APCs (Suhoski et al., 2007). T cells generated by different methods have different phenotypes and in vitrolin vivo functions. The development of manufacturing strategies to generate T cells with maximal anti-tumor activities in vivo will significantly impact T-cell-based adoptive immunotherapy. All current $T$ cell manufacturing procedures require antibodies, which are 
limiting factors and potential impediments due to both their cost and supply when large quantities of expanded $T$ cells are required. Moreover, the mouse origin of the antibodies may be carried over to the $\mathrm{T}$ cell products, potentially rendering them immunogenic and thereby limiting the therapeutic efficacy of the infused T cells. In our previous report, a comparison of $\mathrm{T}$ cells generated from two methods commonly used in clinical trials showed that compared with OKT3/IL-2-stimulated T cells, CD3/CD28-Dynabead-stimulated $\mathrm{T}$ cells were more uniformly central memory cells with a significantly potent ability to control leukemia in Nalm6 mice model following intravenous infusion (Barrett et al., 2014). In our current study, intraperitoneal injection of mesothelin CAR RNA-electroporated T cells generated by OKT3/IL-2 stimulation achieved a rapid and sustained reduction in disease burden than those generated using CD3/CD28 Dynabead against intraperitoneal human-derived mesothelioma tumors that had grown in mice for 56 days before treatment (Campagnolo et al., 2004; Zhao et al., 2010). Furthermore, we found that $T$ cells could be efficiently stimulated and expanded by direct electroporation of PBMCs with mRNA encoding a chimeric membrane protein consisting of a single-chain variable fragment (scFv) against CD3 (OKT3) and the intracellular domains of CD28 and 4-1BB (OKT3-28BB) in the presence of IL-2. We also found that co-electroporation with other RNA molecules, such as CD86 and 4-1BBL, can further change the phenotype and function of OKT328BB RNA-electroporated T cells (RNA-T cells). Interestingly, T cells expanded by co-electroporation of OKT3-28BB with CD86 and 4-1BBL showed less differentiated phenotypes, although they still maintained a tumor lytic ability as potent as that of OKT3/IL-2-stimulated T cells. In different tumor mouse models, T cells expanded from OKT3-28BB/ CD86/4-1BBL RNA electroporation showed anti-tumor activities superior to those of OKT3/IL-2 T cells and similar to those of CD3/CD28 Dynabead T cells. Hence, T cells with both a young phenotype and potent killing ability can be generated by RNA electroporation, and this T cell manufacturing procedure can be potentially further optimized by simply co-delivering other splices of RNA.

\section{RESULTS}

RNA CAR-transferred T cells expanded via OKT3/IL-2 were heterogeneous in phenotype and had enhanced and persistent function in vitro

By comparing the phenotype of the expanded CD3/CD28 Dynabead T cells and the OKT3/IL-2 T cells, it was found that the CD3/CD28 Dynabead $T$ cells had a larger central memory population, as evidenced by $79.4 \% \mathrm{CD}^{2} 5 \mathrm{RO}^{+} /$ $\mathrm{CCR}^{+}$(versus $63.5 \%$ for OKT3 T cells, $P<0.01$ ) with a uniformly younger phenotype $\left(96.2 \% \mathrm{CD} 2 \mathrm{~L}^{+} / \mathrm{CD}^{2} 8^{+}\right.$versus $34.6 \%$ for OKT3 T cells, $P<0.01$ ) (Fig. 1A). The T cells were transiently transferred with a CD19-BBZ CAR by RNA electroporation, and although the CAR expression levels at different time points were similar (Fig. 1B), the OKT3/IL-2 T cells demonstrated increased and sustained antigen-specific lytic activities, as evidenced by both a 4-h CTL killing assay and a CD107a assay, compared with the CD3/CD28 Dynabead T cells (Fig. 1C and 1D). After stimulation by CD19 positive leukemia lines, the CD3/CD28 Dynabead T cells and OKT3/IL-2 T cells secreted similar amounts of IFN-gamma. However, the OKT3/IL-2 T cells produced significantly lower amounts of $\mathrm{IL}-2$. This decreased $\mathrm{IL}-2$ production and increased lytic activity in the OKT3/IL-2 T cells suggests that the OKT3/IL-2 T cells are more differentiated toward effector memory cells, with increased direct tumor-controlling ability and decreased migration and proliferation potential. This finding was supported by our previous report on xenograft models of Nalm6 leukemia, in which CD3/CD28 Dynabead T cells proliferated earlier and to a greater extent than did OKT3/IL-2 T cells, resulting in better disease control. This phenomenon occurred because the Dynabead T cells had a younger phenotype or higher proliferative capacity (Barrett et al., 2014). The finding that OKT3/IL-2 T cells have an more differentiated phenotype and an increased in vitro lytic ability suggests that these T cells may have more potent anti-tumor activity if they are locally administered, such as in a situation where direct anti-tumor potency is more important than migration and proliferation. As shown in Figure $2 \mathrm{~A}$ and $2 \mathrm{C}$, in an intraperitoneal mesothelioma mouse model, a single dose of 25 million CAR RNA-electroporated T cells was injected intraperitoneally 56 days post-tumor inoculation. A rapid and greater reduction in disease burden was noted in the mice treated with ss1BBZ CAR T cells expanded with OKT3/IL-2 compared with ss1BBZ CAR T cells expanded with CD3/CD28 Dynabead. Due to the development of nonspecific T cell/tumor alloreactivity and severe GVHD (data not shown), the experiment was terminated on day 84 posttumor inoculation. Human T cells $\left(\mathrm{hCD} 45^{+} / \mathrm{hCD}^{+}\right)$in the peripheral blood of the treated mice were measured using a Trucount flow assay, and there were significantly more $\mathrm{T}$ cells in the mice treated with ss1.BBZ CD3/CD28 Dynabead T cells than in those treated with either the control CD19.BBZ CD3/CD28 bead T cells or the ss1.BBZ OKT3/IL-2 T cells (Fig. 2B).

T cells can be stimulated and expanded by electroporating mRNA encoding a chimeric membrane protein consisting of an scFv against CD3 from OKT3 and the intracellular domains of CD28 and 4-1BB

To further improve the $\mathrm{T}$ cell manufacturing procedure, we developed a novel $T$ cell stimulation and expansion method in which PBMCs were electroporated with RNA encoding a chimeric membrane protein consisting of an ScFv against CD3 and the intracellular domains of CD28 and 4-1BB (OKT3-28BB). Activation and expansion methods for most $\mathrm{T}$ cells require OKT3, a CD3 antibody, which is of mouse origin 

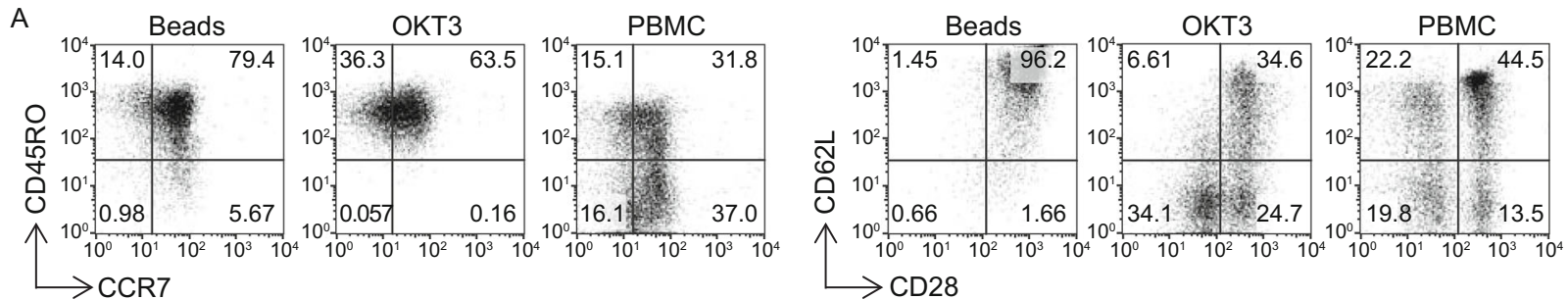

B
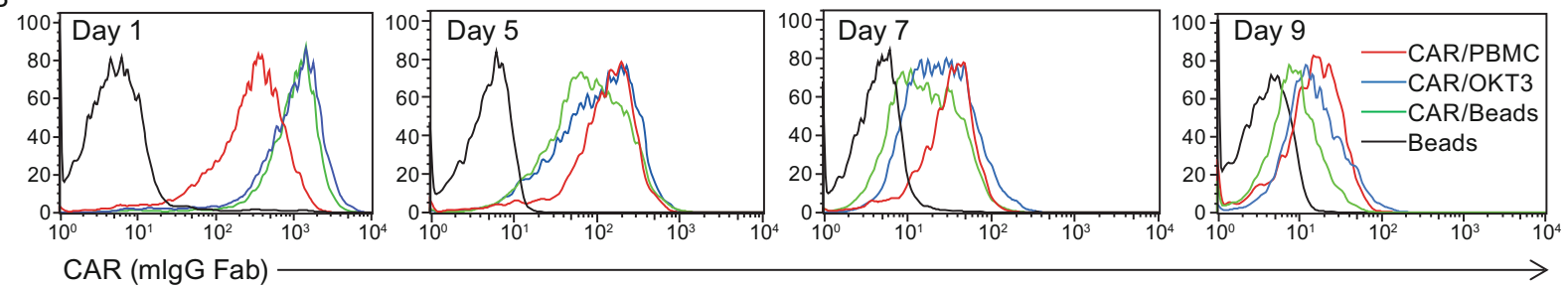

CAR (mlgG Fab)
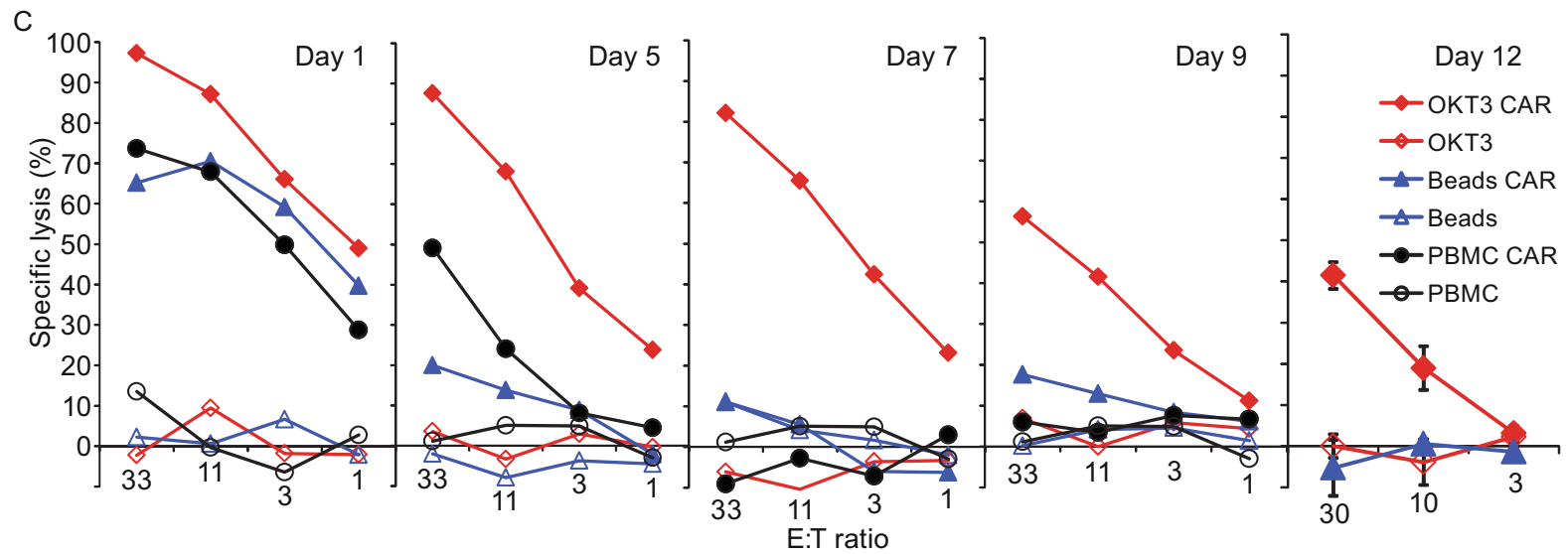

D
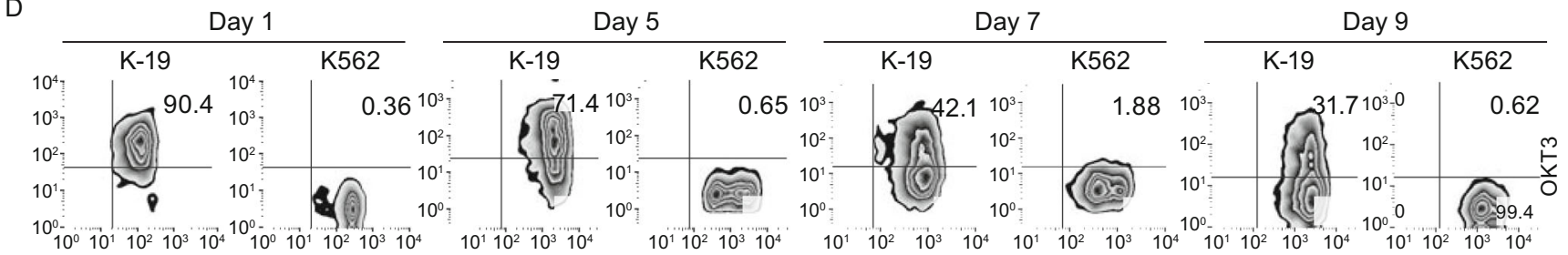

\begin{tabular}{ll} 
Day 9 \\
\hline K-19 K562
\end{tabular}
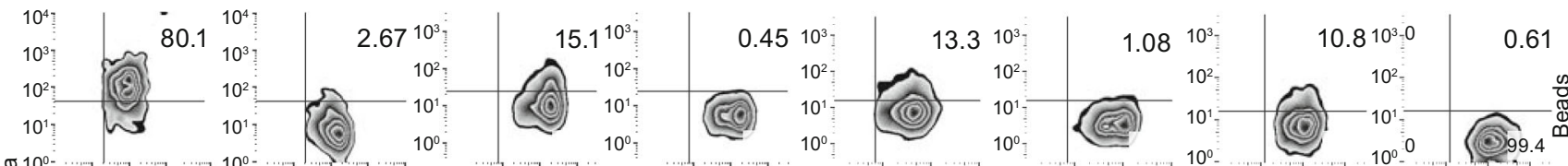

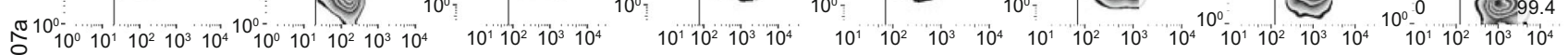
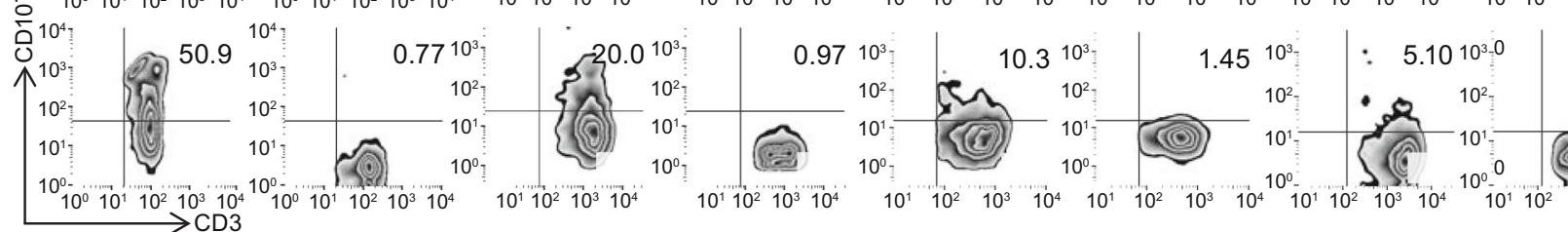

1.30

Figure 1. In vitro function comparison of CD3/CD28 Dynabead-stimulated (Beads) and OKT3/IL-2-stimulated (OKT3) T cells. (A) Phenotype of the expanded T cells, compared with T cells from non-stimulated PBMCs. (B) CAR expression of CD19-BBZ CAR RNA-transferred T cells at different time points post-RNA electroporation. (C) Lytic activity against Nalm6 in a 4-h flow cytometrybased CTL assay for CAR RNA-transferred T cells at different time points post-RNA electroporation. (D) CD107a detection of T cells stimulated by K562-CD19 (K-19) at different time points post-RNA electroporation. (E) Cytokine production of CD19-BBZ CAR RNAtransferred T cells. 
Figure 1. continued.
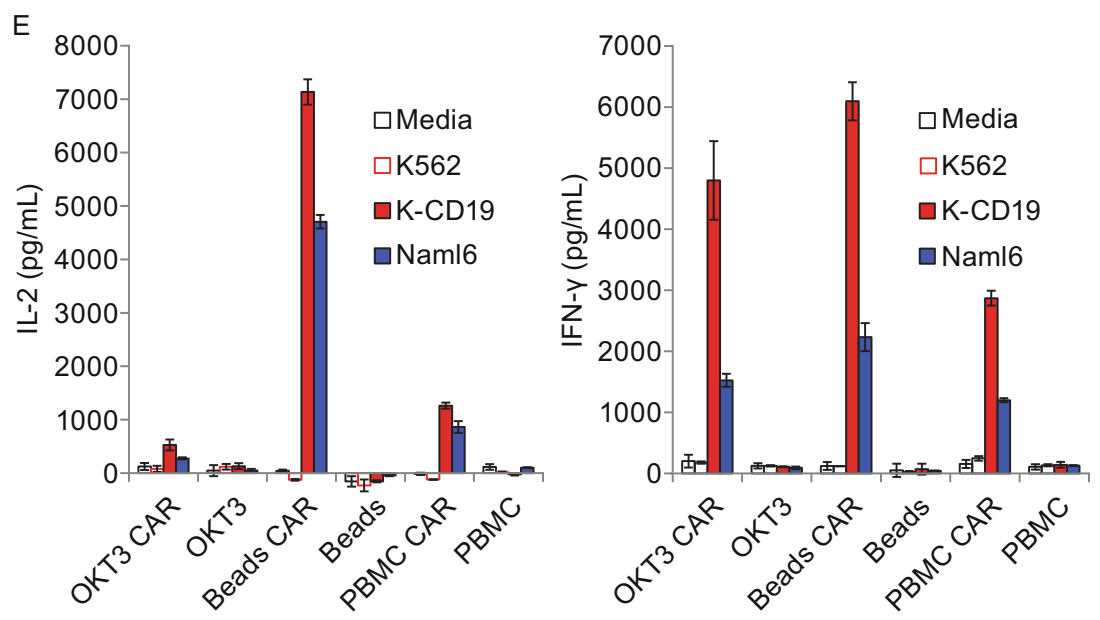

A

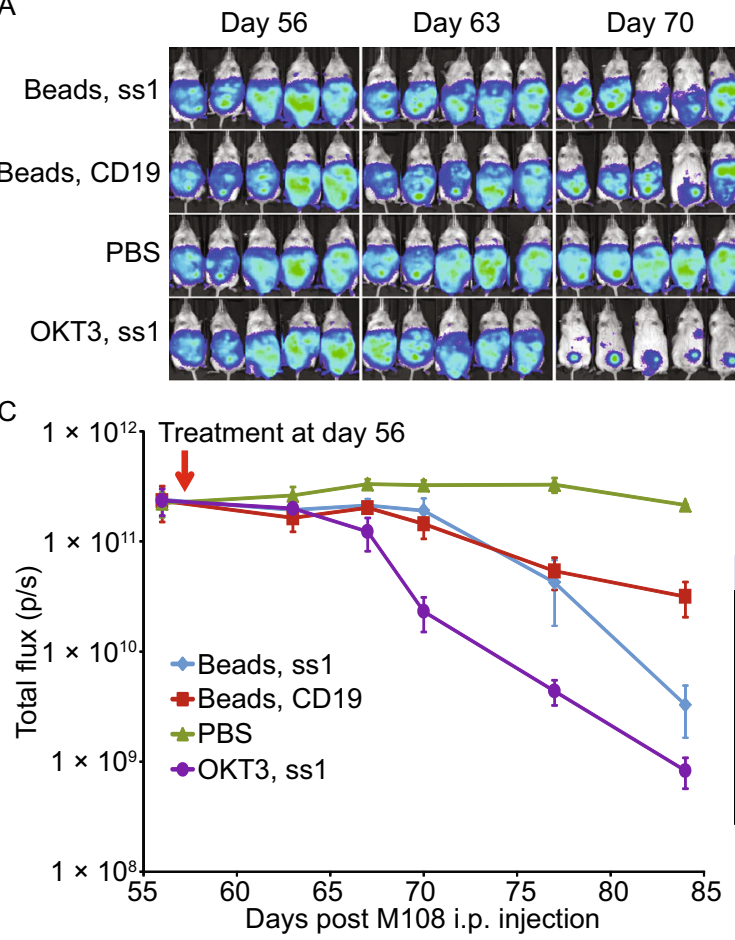

Day 77

Day 84
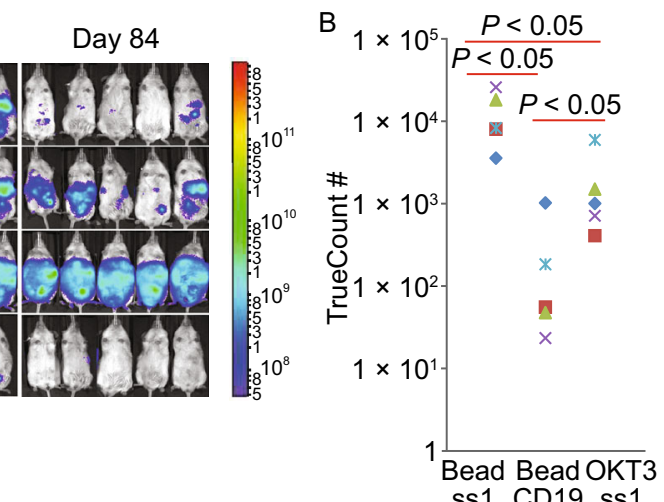

One-way analysis of variance and unpaired $t$ test

\begin{tabular}{|c|c|c|c|c|c|c|}
\hline & 56 & 63 & 67 & 70 & 77 & 84 \\
\hline One-way analysis of variance & ns & $\mathrm{ns}$ & ** & 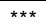 & 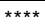 & 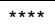 \\
\hline \multirow{3}{*}{$\begin{array}{l}\text { Beads, ss1 vs. Beads, CD19 } \\
\text { Beads, ss1 vs. PBS } \\
\text { Beads, Ss1 vs. OKT3, ss1 }\end{array}$} & ns & ns & $\mathrm{ns}$ & ns & $\mathrm{ns}$ & * \\
\hline & ns & ns & ns & ns & *** & $* * * *$ \\
\hline & ns & ns & ns & * & ns & ns \\
\hline \multirow{3}{*}{$\begin{array}{c}\text { Beads, CD19 vs. PBS } \\
\text { Beads, CD19 vs. OKT3, ss1 } \\
\text { PBS vs. OKT3, ss1 }\end{array}$} & ns & ns & * & ** & $\star \star \star *$ & $\star \star * \star *$ \\
\hline & $\mathrm{ns}$ & ns & ns & * & * & * \\
\hline & ns & ns & ** & ***** & $\star * \star *$ & $\star * * *$ \\
\hline
\end{tabular}

Figure 2. Treatment of advanced vascularized tumors in mice with RNA CAR T cells. (A) Visual representation of disease burden in mice with an M108 tumor treated with expanded T cells. Disseminated intraperitoneal (i.p.) tumors were established in NSG mice ( $n=5$ per group) via injection with $8 \times 10^{6}$ M108-Luc cells. Beginning on day 56, a single dose of RNA CAR-electroporated T cells $\left(2.5 \times 10^{7}\right)$ was injected (i.p.). (B) Detection of human T cells in the peripheral blood of treated mice 40 days post-treatment. Human $\mathrm{CD} 45^{+}$cells were detected using a Trucount flow assay. (C) BLI data and statistical analysis for the experiment. Bars, SE. A greater reduction in disease burden was noted in the mice treated with T cells expanded with OKT3 and expressing ss1BBZ CAR compared with all other groups.

and can be carried into the $T$ cell products. The mouse $A b$ carried over to the $T$ cells could potentially cause an immunoreaction against the infused $T$ cells, thus negatively affecting the treatment. PBMCs from healthy donors were electroporated with in vitro transcribed RNA encoding OKT328BB and the introduced OKT3-28BB can be detected on the cell surface $18 \mathrm{~h}$ after electroporation (Fig. S2). The cells were cultured for T cell expansion and compared with CD3/ CD28 Dynabead-stimulated T cells. T cells stimulated by the electroporation of OKT3-28BB RNA (RNA-T cells) expanded as efficiently as the CD3/CD28 Dynabead T cells (Fig. 3A). Phenotype analysis confirmed that the CD3/CD28 Dynabead T cells were uniformly central memory T cells $(91.5 \%$ CD45RO/CCR7 double-positive), with $80.2 \%$ of the cells 
expressing CD62L and CD28. However, the RNA-T cells were more heterogeneous; they had a more differentiated phenotype (50.8\% CD45RO/CCR7 double-positive), and $52.5 \%$ of the cells expressed CD62L and CD28 (Fig. 3B). Except significantly high expression of 2B4 in RNA-T cells, both CD3/CD28 Dynabead T cells and RNA-T cells expressed CTLA4, TIM-3, LAG-3, and PD-1 at the same levels (Fig. S3). Their functions were tested via stimulation with the CD19-positive cell lines K562-CD19, Raji or Nalm6 after the expanded $T$ cells were transferred with CD19-BBZ CAR RNA. CAR was expressed at similar levels in both the CD3/ CD28 Dynabead T cells and RNA-T cells (Fig. 3C), while CD107a was more highly expressed in the RNA-T cells than in the CD3/CD28 Dynabead T cells (Fig. 3D). The heterogeneous phenotype and increased in vitro lytic activity of the RNA-T cells relative to the CD3/CD28 Dynabead $T$ cells indicate that the RNA-T cells are similar to OKT3/IL-2 T cells. However, although the levels of IFN-y secreted by the RNAT cells and OKT3/IL-2 T cells were comparable, IL-2 production was much higher in the RNA-T cells than in the OKT3 T cells after electroporation with CD19-BBZ CAR RNA and stimulation with the CD19-positive cell lines Nalm6, K562-CD19, and Raji (Fig. 3E).

Less differentiated T cells with potent killing ability can be generated by co-electroporation of RNAs encoding OKT3-28BB and co-stimulatory molecules

We next examined whether the co-electroporation of costimulatory molecular ligand RNA for CD86 and 4-1BBL, which provide additional costimulatory signals through $T$ cells' native receptor CD28 and 4-1BB respectively, could further change the phenotype and function of RNA-T cells. T cells co-electroporated with OKT3-28BB, CD86, and 4-1BBL (OKT3-28BB-86BBL) expressed CCR7 and CD62L at levels as high as those in CD3/CD28 Dynabead T cells, which was in contrast to the OKT3-28BB RNA-T cells and OKT3/IL-2 T cells (Fig. 4A). Interestingly, although the OKT3-28BB86BBL RNA-T cells were primarily central memory $\mathrm{T}$ cells, their killing ability was still as strong as that of the OKT3/IL-2 T cells and OKT3-28BB RNA-T cells and was significantly stronger than that of the CD3/CD28 Dynabead-stimulated $T$ cells (Fig. 4B). Hence, T cells with both a less differentiated phenotype and a potent killing ability can be generated by co-electroporation of RNAs encoding OKT3-28BB and the ligands of co-stimulatory molecules, CD86 and 4-1BBL.

\section{Potent in vivo anti-tumor activities of RNA}

electroporated or lentiviral-transduced RNA-T cells

RNA-T cells generated by co-electroporation of OKT3-28BB, CD86, and 4-1BBL were electroporated with RNA encoding an anti-CD19 bi-specific T cell engager (BiTE). The in vivo anti-tumor activity of these RNA-T cells was then tested in a mouse model of Nalm6 leukemia by giving a single dose $\left(1 \times 10^{7}\right)$ of BiTE RNA-electroporated T cells, and the activity was compared with that of Dynabead T cells. A significant tumor reduction was observed for both the RNA-T cells and the Dynabead T cells after the mice were treated, and the tumors regressed to similar levels (Fig. 5A and 5B, $P>0.05$ ). Both treatments significantly prolonged the survival of the treated mice compared with the control mice. Moreover, there was no significant difference in survival between the two treatment groups (Fig. 5C). To test the anti-tumor activity of the RNA-T cells in a solid tumor model, the T cells were transduced via a lentivirus with a 4D5-BBZ CAR against ErbB2. Unlike treating cancer using RNA-transferred T cells with transient anti-tumor activities, where multiple $\mathrm{T}$ cell infusions are needed to achieve long-term tumor repression, lentiviral transduction may provide $\mathrm{T}$ cells with sustained anti-tumor activities. RNA-T cells can be transduced with a lentiviral vector as efficiently as with CD3/CD28 Dynabead T cells (Fig. 6A). In vitro anti-tumor activities, such as CD107a up-regulation (Fig. 6B) and cytokine production (Fig. 6C), were similar between the lentivirus-transduced RNA-T and Dynabead $T$ cells. In an ovarian tumor (SK-OV3) mouse model, CD3/CD28 Dynabead 4D5-BBZ CART cells showed faster tumor control than OKT3-28BB-86BBL RNA-T 4D5BBZ CAR T cells. 4 out of 5 mice bearing large tumors (approximately $200 \mathrm{~mm}^{3}$ before treatment) were cured by 4D5-BBZ CAR-transduced OKT3-28BB-86BBL RNA-T cells, and 5 out of 5 were cured by CD3/CD28 Dynabead 4D5-BBZ CART cells (Fig. 6D). In our previous report comparing CD3/ CD28 Dynabead T cells with OKT3/IL-2 T cells in the Nalm6 leukemia mouse model, the mice were treated with CD19 CAR RNA-electroporated T cells, and we found that OKT3/ IL-2 T cells were inferior to the CD3/CD28 Dynabead T cells in controlling leukemia. Here, we lentiviral-transduced the same CD19 CAR into Dynabead T cells, OKT3-28BB-86BBL RNA-T cells, and OKT3/IL-2 T cells and tested their antileukemia activity in the Nalm6 model, and the OKT3/IL-2 T cells were still inferior to the CD3/CD28 Dynabead T cells in controlling leukemia. While the RNA-T CD19 CART cells were superior to the OKT3/IL-2 T cells in controlling leukemia, they were slightly inferior to the Dynabead CAR T cells (Fig. 6E).

\section{DISCUSSION}

The culture of harvested lymphocytes with a soluble antiCD3 antibody (OKT3) in the presence of interleukin (IL)-2 (Riddell and Greenberg, 1990) has been widely used and continues to be used in current cell therapy trials. Preliminary studies suggest that this method of expansion produces cells that are largely effector memory and effector T cells in phenotype (Gattinoni et al., 2005; Powell et al., 2005). Potential improvements have been explored, including the addition of feeder cells and the use of supplemental cytokines (Yang et al., 2010; Yang et al., 2013). In our current study, we sought to develop a novel T cell ex vivo expansion method that could easily be improved further. It has been 


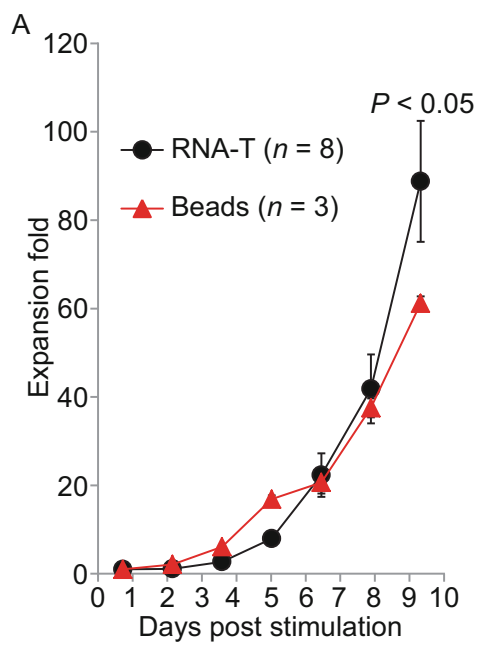

B

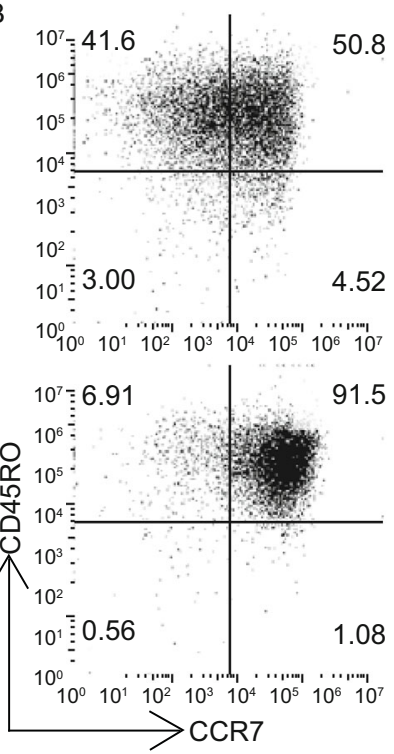

C
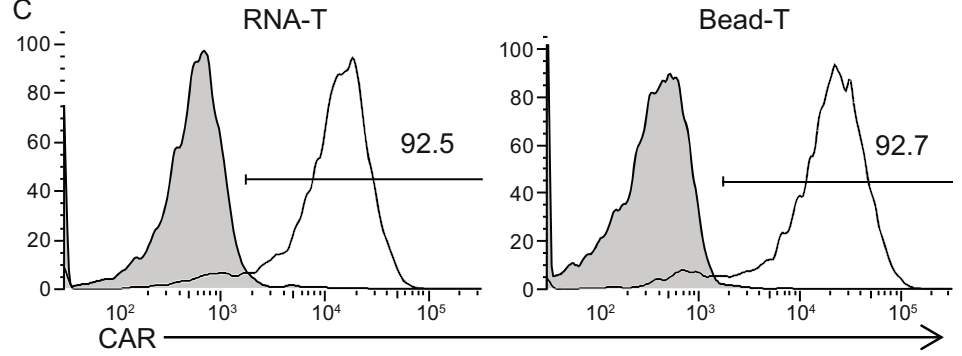

D

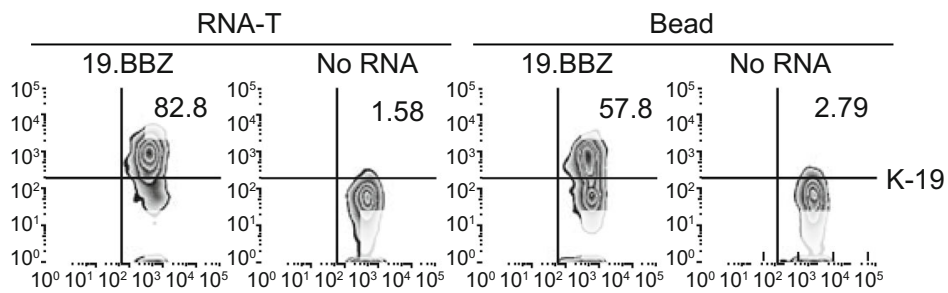

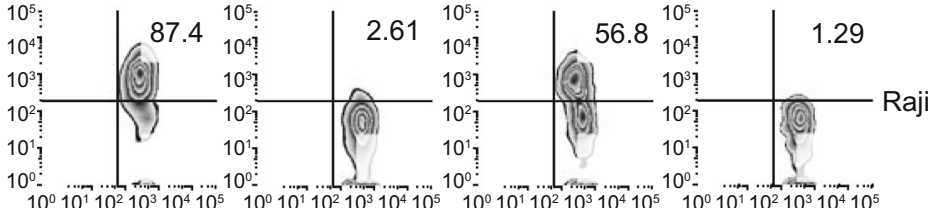

$10^{0} 10^{1} 10^{2} 10^{3} 10^{4} 10^{5} \quad 10^{0} 10^{1} 10^{2} 10^{3} 10^{4} 10^{5} \quad 10^{0} 10^{1} 10^{2} 10^{3} 10^{4} 10^{5} \quad 10^{0} 10^{1} 10^{2} 10^{3} 10^{4} 10^{5}$

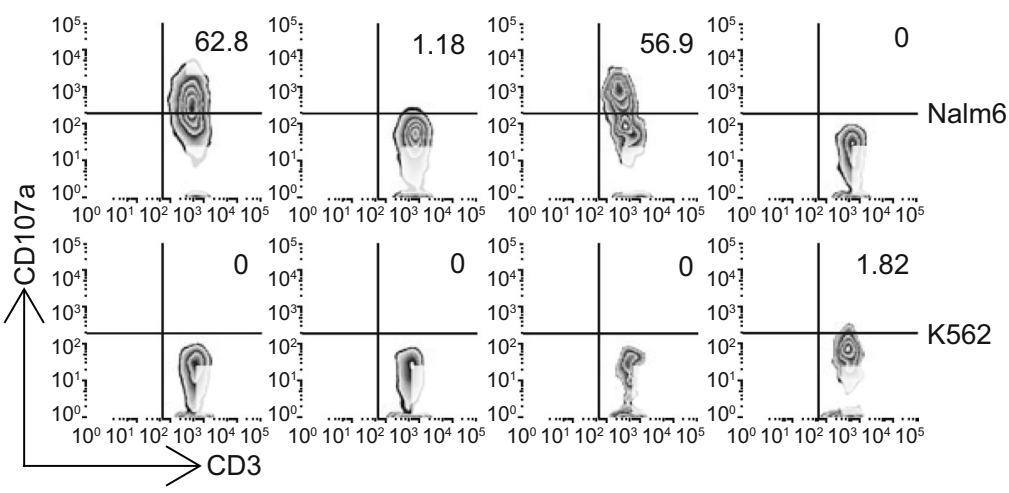

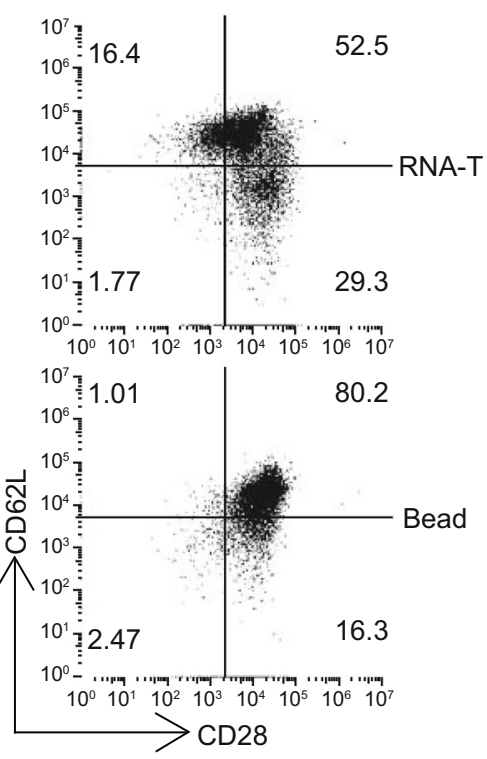

E
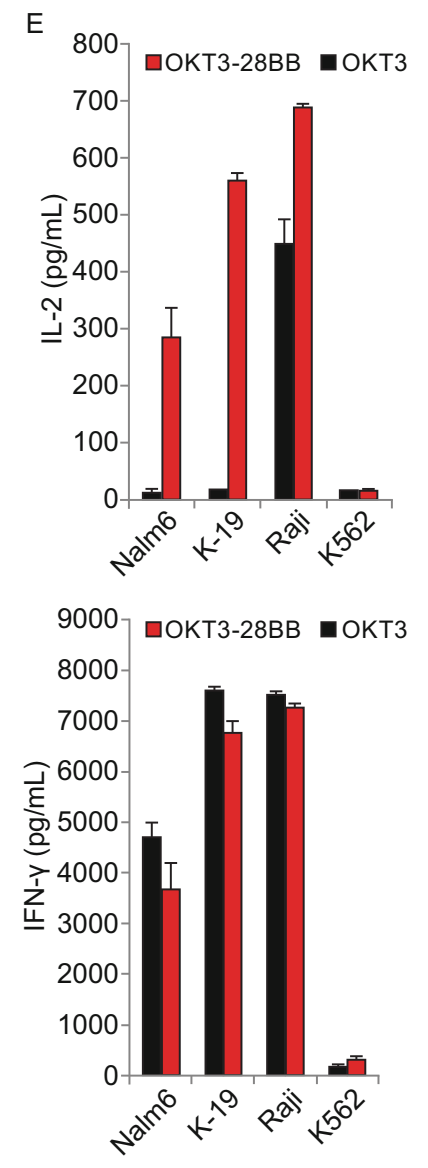
Figure 3. In vitro function of RNA-T cells. (A) Expansion of T cells generated using CD3/CD28 Dynabead (Beads) and OKT3-28BB RNA electroporation (RNA-T). (B) Phenotype of the expanded T cells. Flow cytometry results of day- 9 expanded T cells. (C) CAR expression of CD19-BBZ CAR RNA-transferred $\mathrm{T}$ cells $24 \mathrm{~h}$ post-electroporation. (D) Flow cytometry detection of CD107a for T cells stimulated by CD19-positive cell lines K562-CD19 (K-19), Raji or Nalm6. (E) Cytokine secretion of the $T$ cells detected by ELISA. CD19-BBZ CAR RNAtransferred $T$ cells were stimulated by CD19-positive cell lines K562-CD19 (K-19), Raji or Nalm6 for 24 h, and the supernatant was harvested for cytokine detection.

reported that $T$ cells can be stimulated and expanded by the K562 cell line expressing OKT3 scFv and other immune accessory molecules (Butler et al., 2012) and that synergy between CD28 and 4-1BB co-stimulation can be achieved by including their cytoplasmic domains arranged in tandem (Kloss et al., 2013; Stephan et al., 2007; Watts, 2005). In our study, an OKT3-28BB molecule was designed to combine stimulation (Anti-CD3 scFv is expressed on the cell surface to provide cis- and trans-stimulation to T cells) and co-stimulation (CD28 and 4-1BB, provided in cis form to $T$ cells stimulated via anti-CD3 scFv) in a single structure for efficient human $\mathrm{T}$ cell expansion. It was found that $\mathrm{T}$ cells could only be expanded by starting with PBMCs, not with purified T cells (data not shown), suggesting that some cell components in the PBMCs essentially served as feeder cells to support efficient $\mathrm{T}$ cell expansion.

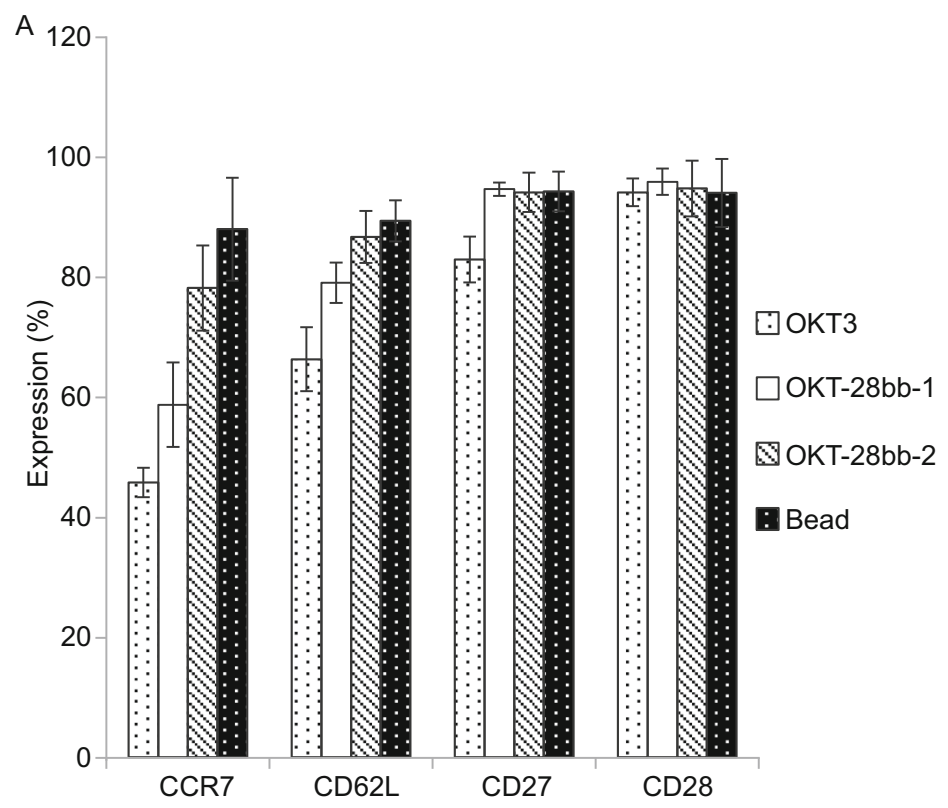

To develop a large number of $T$ cells for adoptive immunotherapy, broad ex vivo cell expansion is required. Observations in murine tumor models and clinical trials have indicated that in vivo tumor treatment efficiency is mostly dependent on the differentiation status of the adoptively transferred $\mathrm{T}$ cells, where $\mathrm{T}$ cell differentiation is inversely related to in vivo anti-tumor effectiveness (Besser et al., 2010; Gattinoni et al., 2005). Thus, the use of "young", less differentiated $\mathrm{T}$ cells with longer telomeres (Zhou et al., 2005b), high expression levels of CD27 and CD28 (Zhou et al., 2005a) and potent tumor lytic activities is crucial for success. In our previous work in a xenograft model of leukemia, we compared two T cell manufacturing methods that are commonly used in adoptive immunotherapy clinical trials, CD3/CD28 Dynabead and OKT3/IL-2. We found that CD3/CD28 Dynabead T cells mediated a greater anti-tumor response when mice were treated via intravenously infusion of CD19 CAR RNA-transferred T cells. This finding was consistent with our current findings that the CD19 CAR lentivirus-transduced CD3/CD28 Dynabead T cells mediate a greater anti-tumor response than do OKT3/IL-2 T cells in the same leukemia mouse model (Fig. 6E). However, compared with the CD3/CD28 Dynabead T cells, the OKT3/IL-2 T cells had a more heterogeneous phenotype and increased and sustained lytic activity in vitro. This finding suggests that the OKT3/IL-2 T cells can more potently induce tumor regression if the T cells are applied locally to the tumor sites, where less differentiated T cells with greater migration and proliferation ability are not as critically important as the $\mathrm{T}$
B

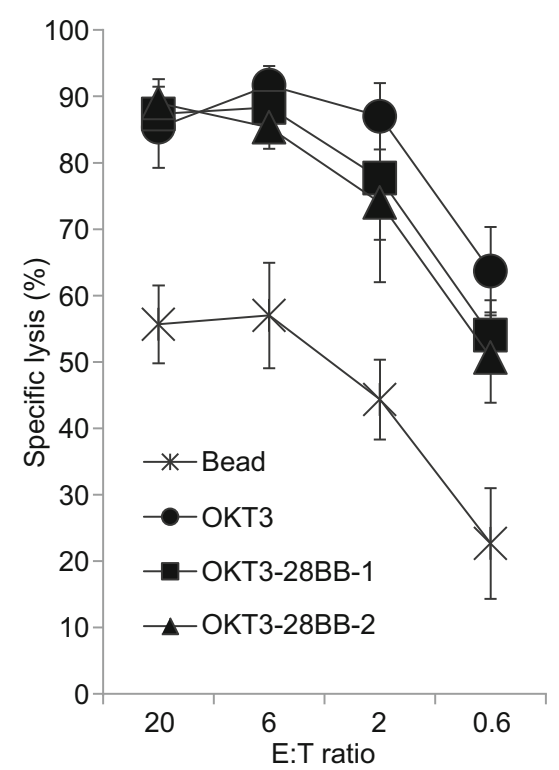

Figure 4. T cells with a less differentiated phenotype and potent lytic activity were expanded by RNA co-electroporation. (A) Detection of less differentiated T cell markers using flow cytometry for T cells generated by OKT3/IL-2 (OKT3), OKT3-28BBZ RNA electroporation (OKT-28bb-1) or OKT3-28BBZ, CD86 and 4-1BBL RNA co-electroporation (OKT-28bb-2). (B) Four-hour flow-based CTL assay of CD19.BBZ CAR RNA-electroporated T cells. 

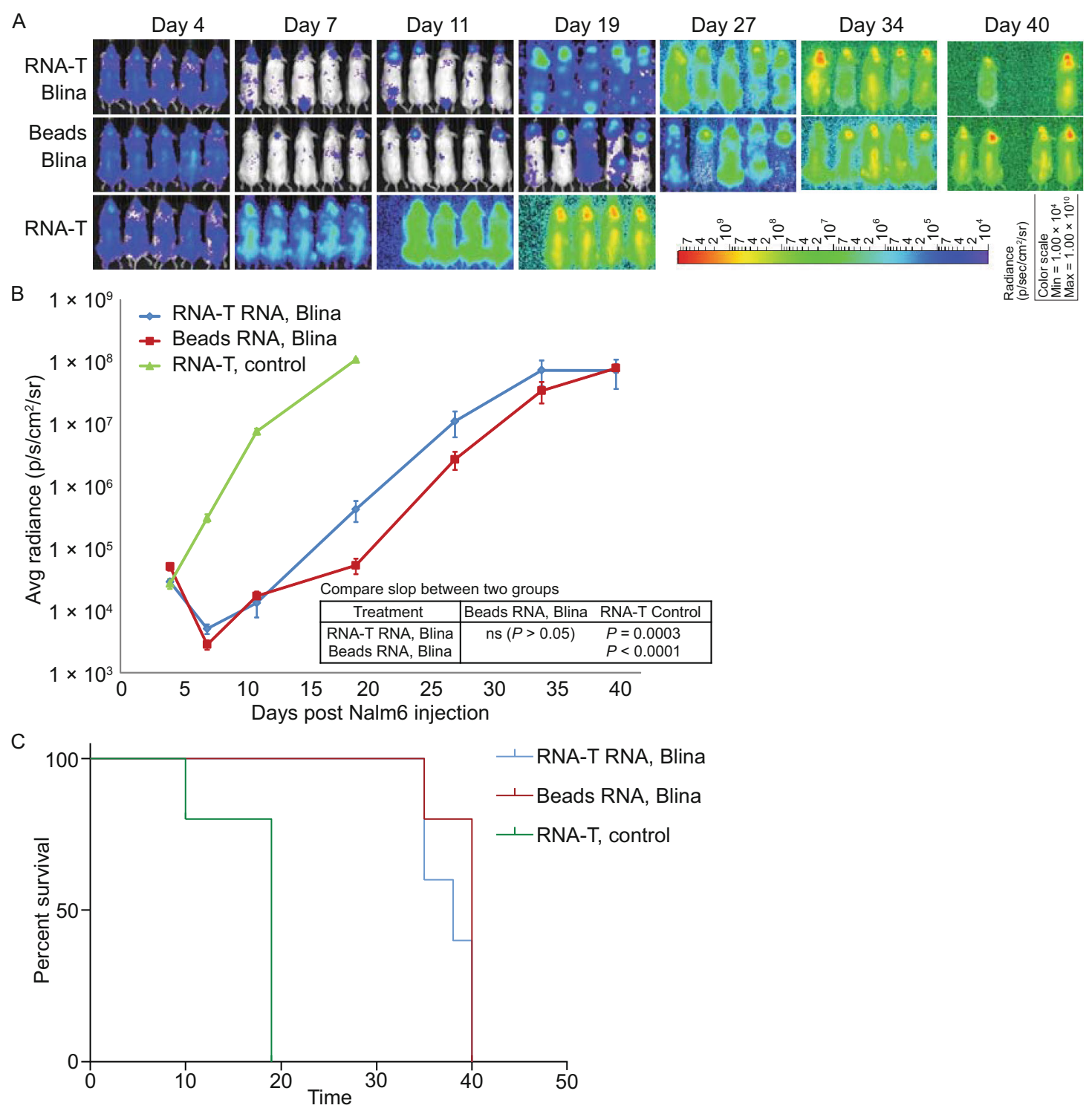

Figure 5. Treatment of Nalm6 leukemia in mice with T cells transferred with RNA encoding CD19-CD3 BiTEs. (A) Leukemia was established in NSG mice ( $n=5$ per group) by intravenous (i.v.) injection with $5 \times 10^{6} \mathrm{Nalm6-CBG}$ cells. Beginning on day 5 , a single dose of $1 \times 10^{7}$ CD19-CD3 BiTE (Blina) RNA-electroporated CD3/CD28 Dynabead T cells (Beads Blina) or RNA-T cells (RNAT Blina) was injected (i.v.), using non-RNA-electroporated RNA-T cells as controls (RNA-T, control). (B) BLI was conducted at the time indicated. (C) Survival curve of the experiment.

cells that are systematically infused. Upon intraperitoneally injecting $T$ cells into mice to treat large pre-existing intraperitoneal human-derived tumors that had been growing in vivo for 56 days, we found a rapid and significant reduction in disease burden in mice receiving $T$ cells expanded with OKT3/L-2 (Fig. 2A and 2C). Significantly (10-fold) fewer T cells were detected in the peripheral blood of mice treated with mesothelin CAR-transferred OKT3/LL-2 T cells compared to mesothelin CAR-transferred CD3/CD28 Dynabead $\mathrm{T}$ cells (Fig. $2 \mathrm{C}$ ). This result suggests that there was less leakage of OKT3/IL-2 T cells administered locally into the peripheral circulation due to their relatively high differentiation status and poor migration ability. This characteristic resulted in quick and improved local anti-tumor activities as well as the potential advantage of increased safety by avoiding unwanted off-target or on-target off-organ toxicities. Therefore, it might be important to consider the use of different $T$ cell manufacturing procedures for treatments that require different $T$ cell infusion routes. T cells expanded by RNA electroporation of OKT328BB are phenotypically and functionally similar to OKT3/L-2 T cells and may be considered an alternative for treating cancers when local T cell administration is required. Instead of developing an alternative to pre-existing $T$ cell manufacturing methods, the major goal of this study was to establish a stimulation 
and expansion platform upon which $\mathrm{T}$ cell quality could be easily improved to meet the required phenotypic characteristics, homing capacities, and potent effector functions for effective cancer immunotherapy (Rosenberg, 2008).

In addition to the direct use of tumor infiltrate lymphocytes (TILs) to treat cancer patients, T lymphocytes can be modified by gene transfer methods to permanently or transiently express therapeutic genes to enhance and expand their therapeutic potential (Maus et al., 2014). The requirements for transiently and permanently genetically modified T cells differ; immediate potent tumor killing ability and proper migration ability are more important for cells with transient gene transfers. By contrast, longevity, robust proliferative potential and the capacity to reconstitute the wide-ranging diversity of the $T$ cell compartment are more critical for cells with permanent gene modifications. Extensive studies have focused on $T$ memory stem cells (TSCM), defined as CD45RO- ${ }^{-}, \mathrm{CD}_{4} \mathrm{RA} \mathrm{A}^{+}$, $\mathrm{CD}^{2} 8^{+}, \mathrm{CD}^{2} 7^{+}, \mathrm{CCR} 7^{+}, \mathrm{CD}_{2} \mathrm{~L}^{+}$, and IL-7Ra ${ }^{+} \mathrm{T}$ cells, with increased levels of IL-2R 3 , LFA-1, CD95, and CXCR3; these studies have demonstrated several distinctive functions of memory cells. Compared with known memory populations, TSCM have shown increased proliferative capacity, greater efficiency in reconstituting immunodeficient hosts, and superior anti-tumor activities in animal models. TSCM identification is directly associated with vaccine design and T-cell-based therapies. TSCM can induce effective tumor regression when a limited number of cells are used. Tumor eradication may involve various components of the immune system. Thus, it is reasonable to transfer $\mathrm{T}$ cells to maintain a constant immunological attack against tumor masses. Therefore, a strategy that generates and expands TSCM-like cells is useful for the development of successful T-cell-based therapies (Gattinoni et al., 2011; Gattinoni et al., 2017). Human TSCM CAR T cells can be generated by CD3/CD28 stimulation with IL-7 and IL-15. CAR-modified CD8 ${ }^{+}$TSCM mediated superior and more durable anti-tumor responses than cells generated with protocols employed in clinical trials (Sabatino et al., 2016). One of the advantages of using RNA electroporation is that multiple splices of RNA can be introduced into T cells with high efficiency. Additionally, T cells can be genetically edited with high efficiency by electroporation of CRISPR/CAS9 (Ren et al., 2016). Thus, by co-introducing OKT3-28BB with RNA encoding other molecules, such as cytokines and co-stimulatory molecules, in combination with the CRIPSR gene editing of critical genes that regulate $T$ cell differentiation, $T$ cells with improved in vivo anti-tumor ability can ultimately be generated.

\section{MATERIALS AND METHODS}

Cell lines and primary human T lymphocyte cultures

The Nalm6 (DSMZ, Braunschweig, Germany), Raji (ATCC, Manassas, VA, USA), and K562 (ATCC, Manassas, VA, USA) cell lines were cultured per the suppliers' instructions. CD19-expressing K562 cells and click beetle green (CBG)-expressing Nalm6 cells were generated as previously described (Barrett et al., 2014). SK-OV3, MCF7, MDA231, and MDA468 cell lines were purchased from the American Type Culture Collection (ATCC, Manassas, VA, USA) and cultured as instructed. PMBCs and purified primary lymphocytes from healthy donors were provided by the University of Pennsylvania Human Immunology Core. Primary T lymphocytes were stimulated and expanded using three different methods: 1. CD3/CD28 Dynabead (Life Technologies, Grand Island, NY) were used as previously described (Barrett et al., 2011). 2. For the OKT3/IL-2 approach, the obtained PBMCs were resuspended at a concentration of $2 \times 10^{6} / \mathrm{mL}$ in culture medium supplemented with $50 \mathrm{ng} / \mathrm{mL}$ OKT3 and $300 \mathrm{IU} / \mathrm{mL} \mathrm{IL}-2$. The lymphocytes were then plated at $2 \mathrm{~mL} /$ well in 24-well plates (Costar). 3. For RNA-T cells, PBMCs were electroporated with OKT3-28BB RNA and re-suspended at a concentration of $2 \times 10^{6} / \mathrm{mL}$ in culture medium supplemented with $300 \mathrm{IU} / \mathrm{mL} \mathrm{IL}-2$; the cells were then cultured and maintained following the same protocol for the OKT3/IL-2 T cells. The expanded $\mathrm{T}$ cells were aliquoted and frozen for further use. The T cells were cryopreserved in a solution of $90 \%$ fetal calf serum and $10 \%$ dimethylsulfoxide (DMSO) at $1 \times 10^{8}$ cells/vial.

\section{Construction of vectors for RNA in vitro transcription (IVT), RNA IVT} and electroporation

IVT vectors for CD19-BBZ, ss1-BBZ CARs, and 4D5-BBZ were constructed as previously described (Barrett et al., 2011; Liu et al., 2015). OKT3-28BB was constructed similarly to a CAR construct without the zeta cytoplasmic region, which includes the $\mathrm{ScFv}$ from OKT3 (VL-linker-VH); the human CD28 hinge/transmembrane region; the CD28 cytoplasmic region; and the 4-1BB cytoplasmic region (Fig. S1). DNA encoding the blinatumomab BiTE (a CD19CD3 bi-specific antibody) was synthesized based on published sequence data from patent US7575923. Human CD86 and 4-1BB cDNA were generated using RT-PCR with RNA isolated from activated T cells; the DNA was confirmed by sequencing. All genes were cloned into a pGEM.64A-based IVT vector (Zhao et al., 2003). The IVT vector was linearized by digestion with the appropriate restriction enzyme, and the mMESSAGE mMACHINE ${ }^{\circledR}$ T7 Ultra kit (Life Technologies) was used to generate the IVT RNA according to the procedure provided with the kit. The frozen stimulated $T$ cells were thawed and cultured overnight before electroporation. Prior to electroporation, the T cells were washed three times with OPTI-MEM and re-suspended in OPTI-MEM at a final concentration of 1-3 $\times 10^{8}$ cells $/ \mathrm{mL}$. Subsequently, $0.1 \mathrm{~mL}$ of the $\mathrm{T}$ cells was mixed with the indicated IVT RNA and electroporated in a 2-mm cuvette (Harvard Apparatus BTX, Holliston, MA) using an ECM830 Electro Square Wave Porator (Harvard Apparatus BTX) (Zhao et al., 2006).

\section{Flow cytometry analysis}

Antibodies were obtained as follows: anti-human CD3 (BD Biosciences, 555335), anti-human CD8 (BD Biosciences, 555366), antihuman CD107a (BD Biosciences, 555801), and anti-human CD137 (BD Biosciences, 555956). The antibodies were incubated with $\mathrm{T}$ cells at $4^{\circ} \mathrm{C}$ for $25 \mathrm{~min}$ and washed twice (PBS with $2 \% \mathrm{FBS}$ ). Mesothelin CAR, ErbB2 CAR, CD19 CAR, and OKT3-28BB expression were detected by biotin-labeled polyclonal anti-mouse $\mathrm{F}(\mathrm{ab}) 2$ antibody (Jackson Immunoresearch). Samples were then 
A

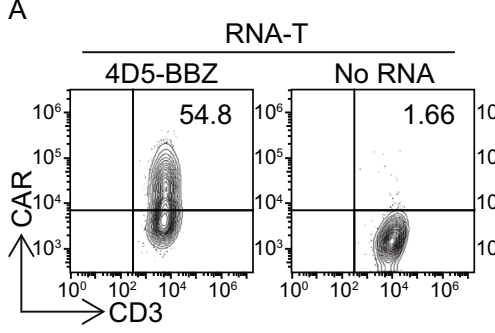

B

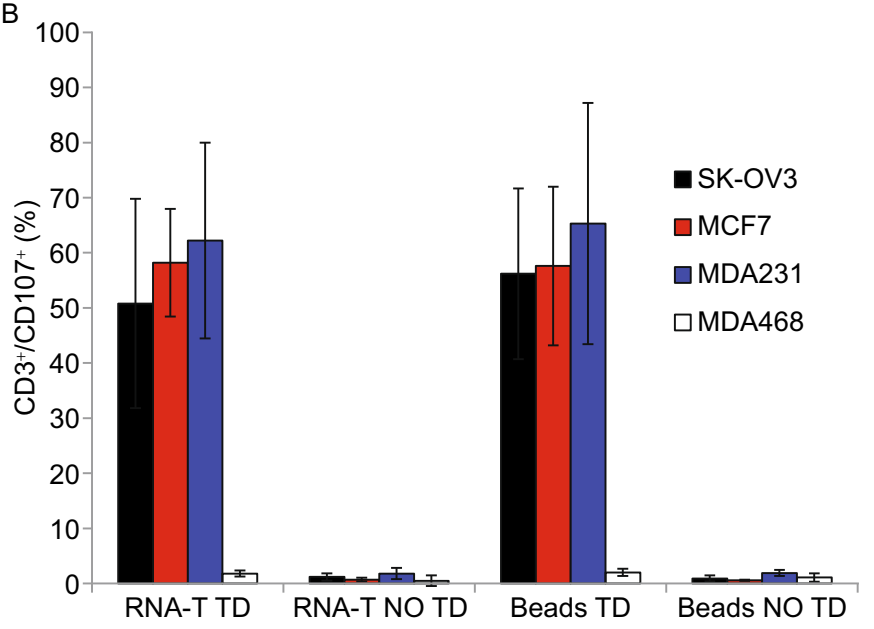

C

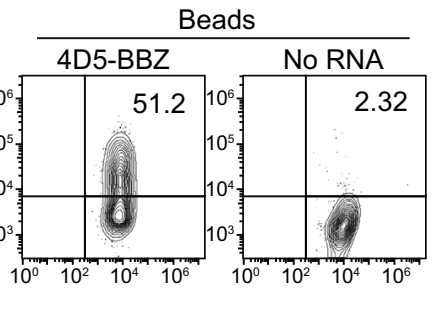

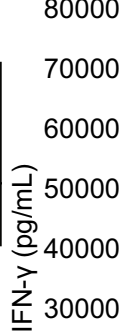

20000

10000

RNA-T TD RNA-T NO TD Beads TD Beads NO TD

30000
25000

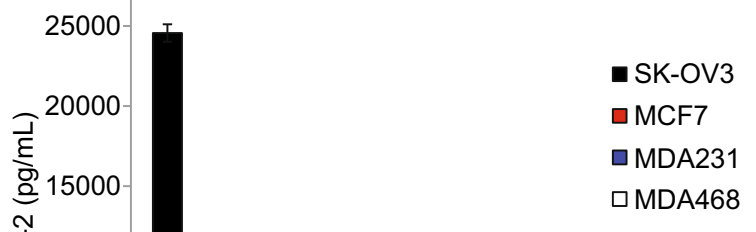

$\square \mathrm{MCF} 7$

- MDA231

口 MDA458

D

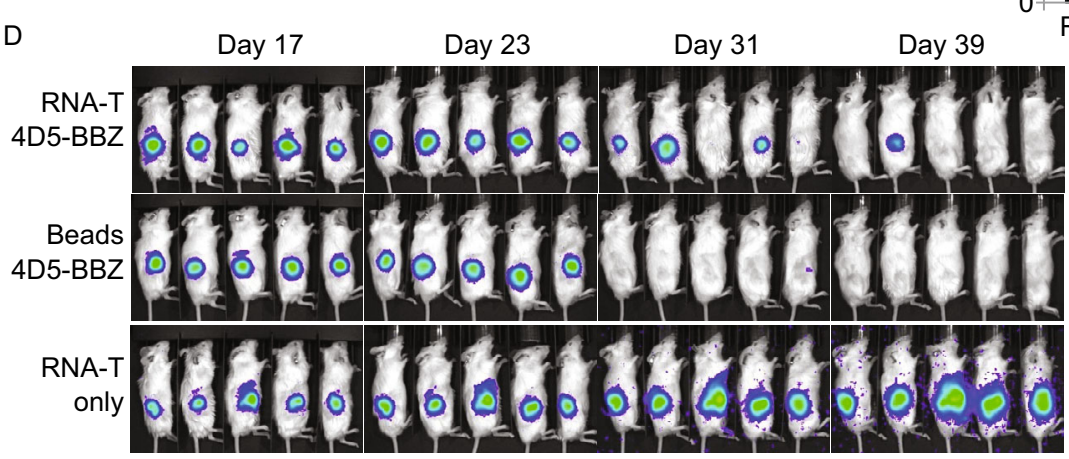

RNA-T TD RNA-T NO TD Beads TD Beads NO TD
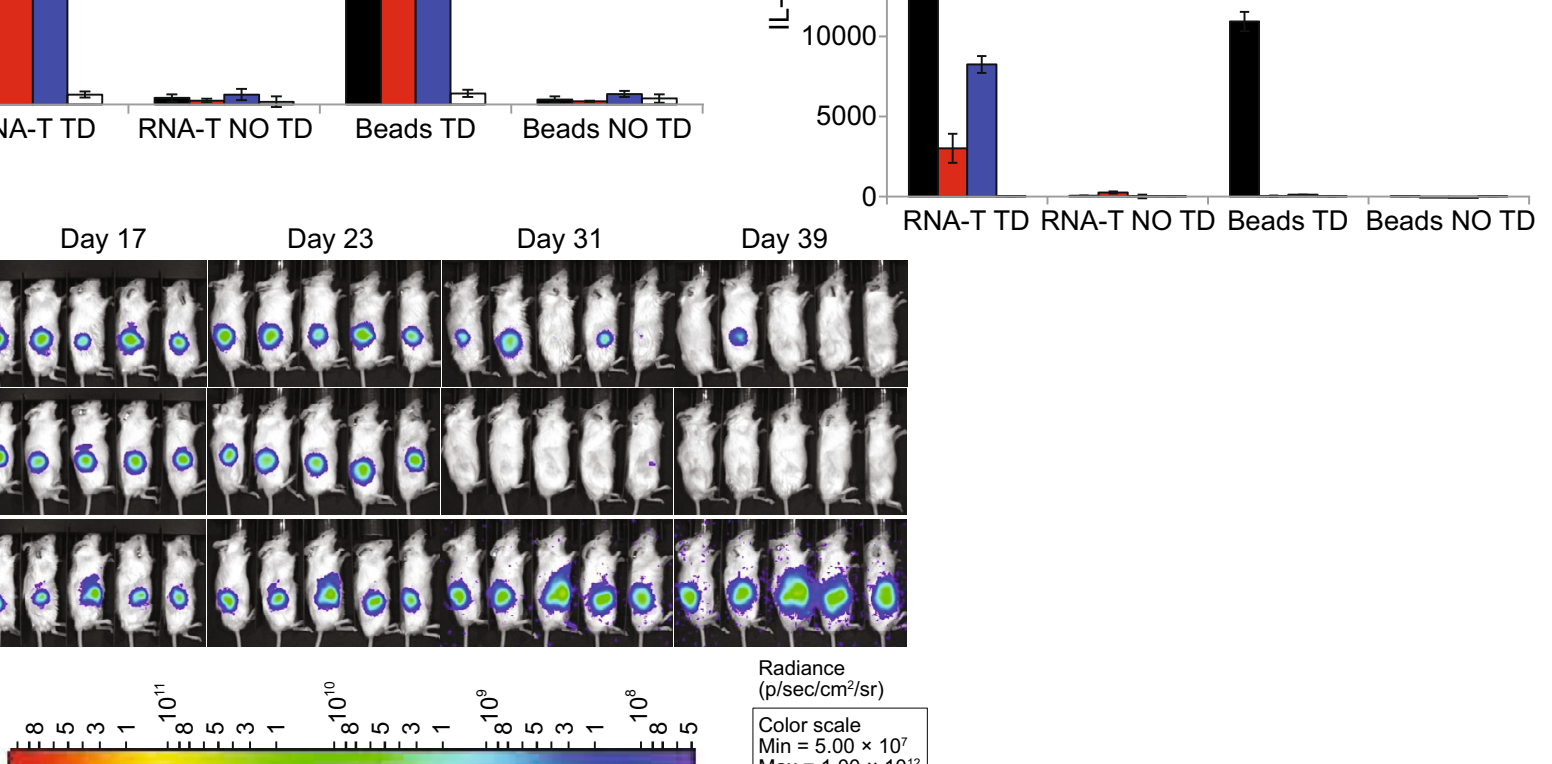

Radiance

$\left(\mathrm{p} / \mathrm{sec} / \mathrm{cm}^{2} / \mathrm{sr}\right)$

Color scale
Min $=5.00 \times 10^{7}$

Max $=1.00 \times 10^{12}$

E

Day $7 \quad$ Day $11 \quad$ Day 18

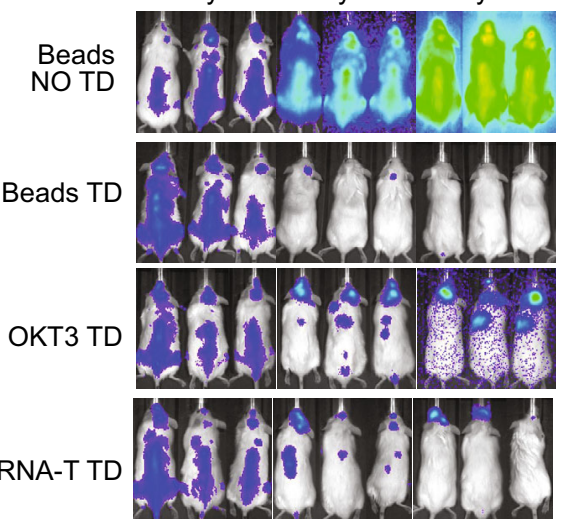

6
$=2$
$=6$
$=60^{9}$
$=210^{8}$
66
$=210^{7}$
66
$=210^{6}$
66
$=210^{5}$

Radiance

(p/sec/cm²/sr)

Color scale

Min $=1.00 \times 10^{5}$

$\operatorname{Max}=1.00 \times 10^{10}$ 
4 Figure 6. Anti-tumor activities of lentiviral-transduced T cells tested in vitro and in mouse tumor models. (A) CAR expression of RNA-T cells (RNA-T) or CD3/CD28 Dynabead T cells (Beads) lentiviral-transduced with an ErbB2 CAR (4D5BBZ). (B) Summary of three independent experiments for detection of CD107a in 4D5-BBZ CAR transduced (TD) T cells stimulated by ErbB2-positive tumor lines SK-OV3, MCF7, and MDA231, using the tumor line MDA468 and non-transduced (NO TD) T cells as negative controls. (C) Cytokine production of T cells stimulated by ErbB2-positive tumor lines SK-OV3, MCF7, and MDA231 and an ErbB2-negative tumor line MDA468. (D) Mice $(n=5)$ were subcutaneously implanted with SK-OV3-CBG tumor cells $\left(5 \times 10^{6}\right.$ cells/mouse) on the flank. The mice were treated with T cells (i.v.) on day 18 after SK-OV3CBG tumor inoculation. A dose of $1 \times 10^{6} \mathrm{CAR}^{+} \mathrm{T}$ cells from either RNA-T cells (RNA-T 4D5-BBZ) or CD3/CD28 Dynabead $T$ cells (Beads 4D5-BBZ) was given as a single injection. Mice treated with non-transduced RNA-T cells (RNA-T only) served as controls. Animals were imaged at the indicated time. (E) CD19 CAR lentiviral-transduced $T$ cells generated by OKT3/IL-2 (OKT3), CD3/CD28 Dynabead (Beads) or OKT328BB/CD86/4-1BBL co-electroporated RNA (RNA-T) were compared in the Nalm6 leukemia model. Leukemia was established in NSG mice ( $n=3$ per group) by i.v. injection with $5 \times 10^{6}$ Nalm6-CBG cells. Beginning on day 7, $1 \times 10^{6}$ CD19-BBZ lentivirus-transduced T cells were injected (i.v.). BLI was conducted at the time indicated.

stained with phycoerythrin-labeled streptavidin (eBioscience, 17-4317-82). Flow cytometry acquisition was performed on either a BD FACSCalibur or Accuri C6 Cytometer (BD Biosciences). Analysis was performed using FlowJo software (Treestar).

\section{Enzyme-linked immunosorbent assay (ELISA)}

Target cells were washed and suspended at $1 \times 10^{6}$ cells $/ \mathrm{mL}$ in R/10 (RPMI1640 with 10\% FBS). One hundred thousand target cells of each type were added to each of 2 wells of a 96-well round bottom plate (Corning). Effector T cell cultures were washed and suspended at $1 \times 10^{6}$ cells $/ \mathrm{mL}$ in R/10. One hundred thousand effector T cells were combined with target cells in the indicated wells of the 96-well plate. Additionally, wells containing only $T$ cells were prepared. The plates were incubated at $37^{\circ} \mathrm{C}$ for 18 to $24 \mathrm{~h}$. After incubation, the supernatant was harvested and subjected to ELISA using standard methods (Pierce, Rockford, IL).

\section{CD107a assay}

The cells were plated at an effector:target $(E: T)$ cell ratio of $1: 1\left(10^{5}\right.$ effectors: $10^{5}$ targets) in $160 \mu \mathrm{L}$ of $\mathrm{R} / 10$ medium in a 96-well plate. An anti-CD107a antibody was added and incubated with the cells for $1 \mathrm{~h}$ at $37^{\circ} \mathrm{C}$ before Golgi Stop was added and incubated for an additional $2.5 \mathrm{~h}$. The anti-CD8 and anti-CD3 antibodies were added and incubated at $37^{\circ} \mathrm{C}$ for $30 \mathrm{~min}$. After incubation, the samples were washed once and subjected to flow cytometry using a BD FACSCalibur. The data were analyzed by FlowJo software.

\section{Flow cytotoxic T lymphocyte (CTL) assay}

A slightly modified version of a 4-h flow cytometry cytotoxicity assay was performed as previously described (Hermans et al., 2004; Zhao et al., 2010).

\section{Mouse xenograft studies}

NSG mice were obtained from the Jackson Laboratory (Bar Harbor, $\mathrm{ME}$ ) or bred in-house under an approved institutional animal care and use committee (IACUC) protocol and maintained under pathogen-free conditions. Six- to ten-week-old NOD-SCID-c ${ }^{-/-}$(NSG) mice were bred in-house under an approved institutional animal care and use committee protocol. For the Nalm6 leukemia model, $1 \times 10^{6}$ Nalm6-CBG cells (Nalm6 transduced via lentivirus with the click beetle green luciferase gene) were injected into each mouse via the tail vein. The T cells were injected via the tail vein either 5 or 7 days after the Nalm6-CBG cells were injected, as indicated. Tumor growth was monitored using bioluminescence imaging (BLI) as previously described (Barrett et al., 2011). For the M108 mesothelioma model (Carpenito et al., 2009; Zhao et al., 2010), animals received intraperitoneal injections with $8 \times 10^{6}$ viable M108-Luc. Tumor growth was monitored using BLI every two weeks for 4 weeks after the tumor was injected. T cells were injected intraperitoneally 8 weeks after tumor inoculation. Tumor growth was monitored using BLI every week after T cell injection. For the SK-OV3 ovarian cancer model, studies were performed as previously described with certain modifications (Liu et al., 2015). Briefly, 6- to 10-week-old NOD-SCID-y ${ }^{-1-}$ (NSG) mice were subcutaneously injected with $5 \times 10^{6}$ SK-OV3-CBG tumor cells in the right flank on day 0 . The mice were treated with $T$ cells via the tail vein on day 18 post-tumor inoculation, when the tumors were approximately $200 \mathrm{~mm}^{3}$ in volume.

\section{Bioluminescence imaging}

Anesthetized mice were imaged using a Xenogen Spectrum system and Living Image v3.2 software. The mice were given an intraperitoneal injection of $10 \mathrm{mg} / \mathrm{kg}$ body weight D-luciferin (Caliper Life Sciences, Hopkinton, MA) suspended in sterile PBS at a concentration of $15 \mathrm{mg} / \mathrm{mL}$ ( $100 \mu \mathrm{L}$ luciferin solution $/ 10 \mathrm{~g}$ mouse body weight). Previous titration of both Nalm6 and human T cells transduced with the firefly luciferase vector revealed a time to peak of photon emission of five minutes, with peak emission lasting 6-10 min. Each animal was imaged alone (for photon quantitation) or in groups of up to 5 mice (for display purposes) in the anterior-posterior prone position at the same relative time point after luciferin injection (6 min). Data were collected until the mid-range of the linear scale was reached (600 to 60,000 counts) or until maximal exposure settings were reached (f stop 1, large binning and $120 \mathrm{~s}$ ) and were then converted to photons $/ \mathrm{s} / \mathrm{cm}^{2} / \mathrm{steradian}$ to normalize each image for exposure time, $f$ stop, binning and animal size. For anatomic localization, a pseudocolor map representing light intensity was superimposed over the grayscale body-surface reference image. For data display purposes, mice without luciferase-containing cells were imaged at maximal settings, and a mean value of $3.6 \times 10^{5} \mathrm{p} / \mathrm{s} / \mathrm{cm}^{2} / \mathrm{sr}$ was obtained. Mice with luciferase-containing Nalm6 typically became moribund with leukemia when the photon flux approached $5 \times 10^{11} \mathrm{p} / \mathrm{s} / \mathrm{cm}^{2} / \mathrm{sr}$, giving a detection range of 6 orders of magnitude. 


\section{Statistical considerations}

Analyses were performed using STATA version 10 (StataCorp, College Station, Texas) or Prism 4 (Graphpad Software, La Jolla, $\mathrm{CA})$. The in vitro data represent the mean of duplicates, and comparisons of means were performed using the Mann-Whitney test. For comparisons among multiple groups, Kruskal-Wallis analyses was performed with Dunn multiple comparison tests to compare individual groups. The leukemia burdens, as measured by BLI of the different groups, were compared with the Mann-Whitney test. The Student's $t$-test was performed to compare differences in T cell proliferation.

\section{ACKNOWLEDGEMENTS}

This study was supported by research grant R01CA120409 $(\mathrm{CHJ}$, $\mathrm{YZ}$ ) and a research grant from Tmunity Therapeutics Inc. (YZ).

\section{COMPLIANCE WITH ETHICS GUIDELINES}

Xiaojun Liu, Carl H. June, and Yangbing Zhao have financial interests due to intellectual property and patents in the field of cell and gene therapy. Conflicts of interest are managed in accordance with University of Pennsylvania policy and oversight. Yangbing Zhao has received research grant from Tmunity Therapeutic Inc. Shuguang Jiang, Chongyun Fang, Hua Li, Xuhua Zhang and Fuqin Zhang declare that they have no Conflicts of interest. All institutional and national guidelines for the care and use of laboratory animals were followed. This article does not contain any studies with human subjects performed by the any of the authors.

\section{AUTHORSHIP}

XL., S.J., C. F., H.L., X.Z., F.Z. performed research. X.L., C.H.J., Y.Z. designed the research, and X.L., Y.Z. wrote the paper.

\section{OPEN ACCESS}

This article is distributed under the terms of the Creative Commons Attribution 4.0 International License (http://creativecommons.org/ licenses/by/4.0/), which permits unrestricted use, distribution, and reproduction in any medium, provided you give appropriate credit to the original author(s) and the source, provide a link to the Creative Commons license, and indicate if changes were made.

\section{REFERENCES}

Barrett DM, Zhao Y, Liu X, Jiang S, Carpenito C, Kalos M, Carroll RG, June CH, Grupp SA (2011) Treatment of advanced leukemia in mice with mRNA engineered T cells. Human Gene Ther 22:1575-1586

Barrett DM, Singh N, Liu X, Jiang S, June CH, Grupp SA, Zhao $Y$ (2014) Relation of clinical culture method to T-cell memory status and efficacy in xenograft models of adoptive immunotherapy. Cytotherapy 16:619-630
Besser MJ, Shapira-Frommer R, Treves AJ, Zippel D, Itzhaki O, Hershkovitz L, Levy D, Kubi A, Hovav E, Chermoshniuk $\mathrm{N}$ et al (2010) Clinical responses in a phase II study using adoptive transfer of short-term cultured tumor infiltration lymphocytes in metastatic melanoma patients. Clin Cancer Res 16:2646-2655

Brentjens RJ, Davila ML, Riviere I, Park J, Wang X, Cowell LG, Bartido S, Stefanski J, Taylor C, Olszewska M et al (2013) CD19-targeted Tcells rapidly induce molecular remissions in adults with chemotherapyrefractory acute lymphoblastic leukemia. Sci Transl Med 5:177ra138

Butler MO, Imataki O, Yamashita Y, Tanaka M, Ansen S, Berezovskaya A, Metzler G, Milstein MI, Mooney MM, Murray AP et al (2012) Ex vivo expansion of human CD8+ T cells using autologous CD4+ T cell help. PloS ONE 7:e30229

Campagnolo C, Meyers KJ, Ryan T, Atkinson RC, Chen YT, Scanlan MJ, Ritter G, Old LJ, Batt CA (2004) Real-Time, label-free monitoring of tumor antigen and serum antibody interactions. J Biochem Biophys Methods 61:283-298

Carpenito C, Milone MC, Hassan R, Simonet JC, Lakhal M, Suhoski MM, Varela-Rohena A, Haines KM, Heitjan DF, Albelda SM et al (2009) Control of large, established tumor xenografts with genetically retargeted human $T$ cells containing CD28 and CD137 domains. Proc Natl Acad Sci USA 106:3360-3365

Gattinoni L, Klebanoff CA, Palmer DC, Wrzesinski C, Kerstann K, Yu Z, Finkelstein SE, Theoret MR, Rosenberg SA, Restifo NP (2005) Acquisition of full effector function in vitro paradoxically impairs the in vivo antitumor efficacy of adoptively transferred CD8+ T cells. J Clin Investig 115:1616-1626

Gattinoni L, Lugli E, Ji Y, Pos Z, Paulos CM, Quigley MF, Almeida JR, Gostick E, Yu Z, Carpenito C et al (2011) A human memory T cell subset with stem cell-like properties. Nature medicine 17:1290-1297

Gattinoni L, Speiser DE, Lichterfeld M, Bonini C (2017) T memory stem cells in health and disease. Nat Med 23:18-27

Hermans IF, Silk JD, Yang J, Palmowski MJ, Gileadi U, McCarthy C, Salio M, Ronchese F, Cerundolo V (2004) The VITAL assay: a versatile fluorometric technique for assessing CTL- and NKTmediated cytotoxicity against multiple targets in vitro and in vivo. $\mathrm{J}$ Immunol Methods 285:25-40

Kloss CC, Condomines M, Cartellieri M, Bachmann M, Sadelain M (2013) Combinatorial antigen recognition with balanced signaling promotes selective tumor eradication by engineered T cells. Nat Biotechnol 31:71-75

Lee DW, Kochenderfer JN, Stetler-Stevenson M, Cui YK, Delbrook C, Feldman SA, Fry TJ, Orentas R, Sabatino M, Shah NN et al (2015) T cells expressing CD19 chimeric antigen receptors for acute lymphoblastic leukaemia in children and young adults: a phase 1 dose-escalation trial. Lancet 385:517-528

Levine BL, Bernstein WB, Connors M, Craighead N, Lindsten T, Thompson CB, June CH (1997) Effects of CD28 costimulation on long-term proliferation of CD4+ $\mathrm{T}$ cells in the absence of exogenous feeder cells. J Immunol 159:5921-5930

Liu X, Jiang S, Fang C, Yang S, Olalere D, Pequignot EC, Cogdill AP, Li N, Ramones M, Granda B et al (2015) Affinity-tuned ErbB2 or EGFR chimeric antigen receptor T cells exhibit an increased therapeutic index against tumors in mice. Cancer Res 75:35963607 
Maus MV, Fraietta JA, Levine BL, Kalos M, Zhao Y, June CH (2014) Adoptive immunotherapy for cancer or viruses. Ann Rev Immunol 32:189-225

Morgan RA, Dudley ME, Wunderlich JR, Hughes MS, Yang JC, Sherry RM, Royal RE, Topalian SL, Kammula US, Restifo NP et al (2006) Cancer regression in patients after transfer of genetically engineered lymphocytes. Science 314:126-129

Porter DL, Levine BL, Kalos M, Bagg A, June CH (2011) Chimeric antigen receptor-modified $T$ cells in chronic lymphoid leukemia. N Engl J Med 365:725-733

Powell DJ Jr, Dudley ME, Robbins PF, Rosenberg SA (2005) Transition of late-stage effector T cells to CD27+ CD28+ tumorreactive effector memory $T$ cells in humans after adoptive cell transfer therapy. Blood 105:241-250

Ren J, Liu X, Fang C, Jiang S, June CH, Zhao Y (2016) Multiplex genome editing to generate universal CAR T cells resistant to PD1 inhibition. Clin Cancer Res 23(9):2255-2266

Riddell SR, Greenberg PD (1990) The use of anti-CD3 and antiCD28 monoclonal antibodies to clone and expand human antigen-specific T cells. J Immunol Methods 128:189-201

Rosenberg SA (2008) Overcoming obstacles to the effective immunotherapy of human cancer. Proc Natl Acad Sci USA 105:12643-12644

Sabatino M, Hu J, Sommariva M, Gautam S, Fellowes V, Hocker JD, Dougherty S, Qin H, Klebanoff CA, Fry TJ et al (2016) Generation of clinical-grade CD19-specific CAR-modified CD8+ memory stem cells for the treatment of human B-cell malignancies. Blood 128:519-528

Stephan MT, Ponomarev V, Brentjens RJ, Chang AH, Dobrenkov KV, Heller G, Sadelain M (2007) T cell-encoded CD80 and 4-1BBL induce auto- and transcostimulation, resulting in potent tumor rejection. Nat Med 13:1440-1449

Suhoski MM, Golovina TN, Aqui NA, Tai VC, Varela-Rohena A, Milone MC, Carroll RG, Riley JL, June CH (2007) Engineering artificial antigen-presenting cells to express a diverse array of costimulatory molecules. Mol Ther 15:981-988

Watts TH (2005) TNF/TNFR family members in costimulation of T cell responses. Ann Rev Immunol 23:23-68

Yang S, Dudley ME, Rosenberg SA, Morgan RA (2010) A simplified method for the clinical-scale generation of central memory-like CD8+ $\mathrm{T}$ cells after transduction with lentiviral vectors encoding antitumor antigen T-cell receptors. J Immunother 33:648-658

Yang S, Ji Y, Gattinoni L, Zhang L, Yu Z, Restifo NP, Rosenberg SA, Morgan RA (2013) Modulating the differentiation status of ex vivo-cultured anti-tumor $\mathrm{T}$ cells using cytokine cocktails. Cancer Immunol Immunother 62:727-736

Zhao Y, Boczkowski D, Nair SK, Gilboa E (2003) Inhibition of invariant chain expression in dendritic cells presenting endogenous antigens stimulates CD4+ T-cell responses and tumor immunity. Blood 102:4137-4142

Zhao Y, Zheng Z, Cohen CJ, Gattinoni L, Palmer DC, Restifo NP, Rosenberg SA, Morgan RA (2006) High-efficiency transfection of primary human and mouse T lymphocytes using RNA electroporation. Mol Ther 13:151-159

Zhao Y, Moon E, Carpenito C, Paulos CM, Liu X, Brennan AL, Chew A, Carroll RG, Scholler J, Levine BL et al (2010) Multiple injections of electroporated autologous $\mathrm{T}$ cells expressing a chimeric antigen receptor mediate regression of human disseminated tumor. Cancer Res 70:9053-9061

Zhou J, Dudley ME, Rosenberg SA, Robbins PF (2005a) Persistence of multiple tumor-specific T-cell clones is associated with complete tumor regression in a melanoma patient receiving adoptive cell transfer therapy. J Immunother 28:53-62

Zhou J, Shen X, Huang J, Hodes RJ, Rosenberg SA, Robbins PF (2005b) Telomere length of transferred lymphocytes correlates with in vivo persistence and tumor regression in melanoma patients receiving cell transfer therapy. J Immunol 175:70467052 